\title{
Experimenting new design languages in contemporary home design
}

\author{
Francesca Tosi ${ }^{\mathrm{a},},{ }^{*}$, Alessandra Rinaldi ${ }^{\mathrm{b}}$ \\ ${ }^{a}$ Faculty of Architecture, University of Florence, Via San Niccolò 85, 50125 Florence, Italy \\ ${ }^{\mathrm{b}}$ Spring Design ${ }^{\circledR}$, Via Capo di Mondo 56, 50136 Florence, Italy
}

\begin{abstract}
The changes in society at the beginning of this millennium are giving rise to deep transformations in the behavioural trends and tastes of home users, as well as in their lifestyles and consumption patterns. This opens up a wide range of opportunities for innovation within the context of contemporary home design. Due to the emergence of new user profiles, new needs and models are coming to the attention of designers and manufacturing companies. Just think about the new needs resulting from the changing composition of households, new forms of cohabitation and the contemporary multi-ethnic society.
\end{abstract}

Keywords: Ergonomics, User Innovation, Design, Sustainability

\section{Introduction}

The formation of research lines and experimental, crossover design fields, in the areas of Ergonomics, Design and Sustainability comes from an innovative approach towards a more general theme of "design for the person". This approach has emerged in recent years in the fields of Ergonomics for Design, methodological research on the usability of industrial products, and design education.

The specificity and innovative value of the ergonomic approach to design resides in the ability to address the multiplicity of variables that define the product-user interaction (users' features and capabilities, product features and goals and activities for which their use, and the characteristics of the physical and social context) by identifying and interpreting, in turn, the demands that users may express.

In ergonomic terms, any assessment of usability, safety and well-being conditions experienced by the individual in his relationship with products and services - as well as with buildings and urban environments - cannot but stimulate greater focus on the levels of health and safety (and in the broad sense of comfort and discomfort) offered by environmental conditions.
Conversely, the environmental impact assessment of manufacturing processes and product lifecycles shows they are closely linked to the assessment of their impact on health and safety of the individual and the community, and on effective and/or perceived individual wellbeing conditions. So we can talk about common goals observed from two different angles: Ergonomics for Design and Sustainability.

The first step is therefore to identify a common ground among the different areas, in terms of theoretical development and methodological content, and also of operational planning, thus enabling a definition of common languages and common means of intervention.

While it is evident that there is a high level of complexity introduced by an integrated approach between the two different areas - a complexity that arises from the multiplicity of the investigative fields as well as from the methodological and interpretative tools available - the topics springing from the possible integration between different analytical approaches are of great interest.

Addressing the issues of environmental sustainability requires knowledge of the product and an evaluation of the complexity of the transformation processes of raw materials, production processes and

\footnotetext{
*Corresponding autor. E-mail: francesca.tosi@unifi.it
} 
the disposal of products and components, the methods and limits of the disassembly, reuse and transformation processes and, more generally, the environmental impact of each of the individual steps of a product's lifecycle.

In ergonomic terms, the assessment of environmental impact has a direct effect on the assessment of the impact that these elements have on individual health, on the safety conditions offered by the environment and, more generally, on individual and social well-being conditions, and it cannot be separated from the complexity of safety and usability assessments and their evaluation through all the product design and construction steps up to the marketing, exploitation and disposal phases.

Each phase of a product's lifecycle can be evaluated from two different angles - Ergonomics and Sustainability - opening up to different interpretations via which it is possible to understand the needs and expectations of stakeholders and users throughout all the phases of the product's lifecycle.

Technicians, assembly, transport, and warehouse workers, sales personnel, and ultimately, final users of the product. Each figure involved has very different needs and expectations, and equally different safety, health-protection, usability and wellbeing requirements. The same also applies to the steps of collecting, dismantling, reuse, and final disposal of the product.

\section{Design, Ergonomics and Sustainability in contemporary living: intervention objective}

The Design for Sustainability principles require radical rethinking of the production and consumption systems, also in terms of contemporary home design, aimed at encouraging the use of low energy technologies, renewable sources and design solutions able to guide and make users aware of sustainable behaviour.

The objectives set by the European Union plan to combat climate change, epitomized by the motto "2020-20", are expected to reach $20 \%$ of energy production from renewable sources, improving efficiency by $20 \%$, with a $20 \%$ cut in emissions by 2020.

This underlines the need for rethinking of contemporary living, particularly with regard to consumption and environmental impact during the exploitation phase of the Home System, designed to promote the use of energy-efficient technologies and renewable energy sources, and also to provide solutions to help users make environmentally-correct choices.

In particular, the kitchen appears today as the heart of the house, the place where food is stored and prepared, where household waste is produced and disposed off, the ultimate meeting place for the family.

The kitchen is also the home environment where the greatest pollution flows are generated, where the consumption of energy resources is more concentrated and at the same time, the place where investments in technology and innovation are maximized.

The kitchen is a huge technological machine, for which functionality, safety and efficiency are no longer the only reference requirements, but are accompanied by other needs such as flexibility and adaptability, both of technology and equipment, to specific environmental and human needs, dictated by new trends in behaviour and lifestyles.

It also can be stated that the analysis of the environmental impact of the entire 'kitchen system' (meaning all furniture, large appliances and accessory items) quantifies the greatest amount of energy and increased production of waste and pollution, not so much in the production phase of the system (furniture, appliances, etc.), or during postconsumer waste phase, but rather, during the use phase.

If designed and implemented according to the principles of sustainability and reuse, the life-cycle of the total 'kitchen system' which is estimated to last 15-20 years, has the possibility of drastically reducing its environmental impact.

Recent research on this issue has shown that the greatest amounts of energy are consumed in the kitchen due to incorrect use of appliances, such as continuous and unnecessary opening of the refrigerator thus increasing energy consumption, the wasting of water for washing the dishes and using the sink every day, and high energy consumption from incorrect use of electrical ovens, cooker exhaust hoods, etc.

It is therefore necessary to rethink the design of the kitchen space taking into consideration its appliances, furniture and use.

Our research and experimental design is based on the choice of two different approach methods designed to work in synergy: Ergonomics for Design and Design for Sustainability. Both are characterized by high levels of innovation of the design and production processes and the actual quality of the 
finished product, in order to define a policy for intervention tools aimed at raising the overall quality of the results.

The methods of Ergonomics for Design pertaining to the areas of Human Factors and UserCentred Design - allow for guiding the project towards the real needs and expectations of the users and for defining the demands of contemporary users by defining new product use scenarios.

Aided by tools for assessing the environmental impact of the product, the Design for Sustainability directs the project towards the use of sustainable materials and the reduction of environmental impact of the production and working processes, as well as the reduction of consumption during the use phase of the product.

\section{Well-living, innovative solutions for the contemporary kitchen}

The Ergonomics-Design-Sustainability approach is the basis of the "Well-living research project: innovative solutions for the contemporary kitchen".

The research project was developed between 2009 and 2011 during a joint research and teaching experiment in the Bachelor's Degree Course of Design at the University of Florence, funded by the Regione Toscana in 2011.

The project was carried out in collaboration with several kitchen manufacturers and addressed the issue of sustainability in living, and human, environmental wellbeing. The main topic was the kitchen, with special emphasis on furnishings, accessories and large appliances such as steam recovery hoods, kitchens designed for everyone, sinks with water recovery, smart taps, and so on.

The Well-Living project was based on the User Centred Design approach aimed at considering all the variables of the specific use context, and assessing the complexity of their reciprocal interactions.

The survey phase was divided into:

- Analysis of the use context:

who are the users

what is the product

why people use the product where users use the product when users use the product how users use the product
- identification of critical elements

- alternative project/design concepts

- project development.

\section{Results}

The solutions are all designed to experiment radically innovative concepts, both from the technological and use points of view. The aim is to cut the environmental impact of the food system, especially in the use phase, through the application of technologies for producing clean energy, with the redesigning of various components for containing and conserving energy with intelligent exhaust hoods, sinks, stovetops, etc., and the development of design solutions encouraging users to adopt new behavioural patterns for reducing energy consumption and correctly managing domestic waste.

Starting from the redefinition of usability and technology related to furnishings and kitchen accessories, we are trying to define new usage scenarios and radical innovations in the home, which production-wise, focus not only on functional and aesthetic innovation and economic development, but also on guiding the consumer towards environmentfriendly awareness and behaviour.

\subsection{Coming Kitchen}

Ergonomics and environmental sustainability are the key requirements of this project.

The innovation of the compositional structure is found mainly in the Coming Kitchen wall-cupboard area, and more generally, enhanced accessibility to all utensils and work items.

A "horizontal refrigerator" has also been designed, with the top made in glass with a controlled glazing system allowing to select the product before opening the fridge, thus avoiding unnecessary energy loss.

The plumbing system includes a water recycling system.

Thanks to the sink with two outlets, one leading to the drain and the other to the filtration system, water can be purified for reuse in the dishwasher, thus ensuring a considerable savings of resources.

- a market survey (benchmarking) 


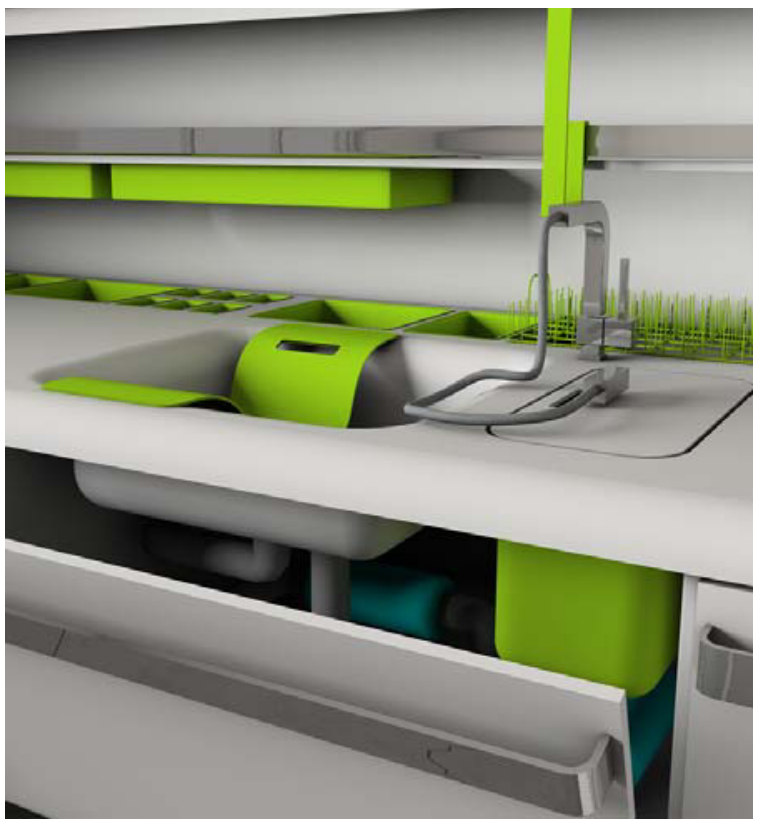

Figure 1. Coming Kitchen, design by Irene Bruni

\subsection{Vega: innovative design and usability for a new concept of kitchen}

The main purpose of the "Vega" project was to create a kitchen that not only combines the concepts of functionality and aesthetic innovation, but also fits perfectly into a sustainable development scheme.

From the spatial standpoint it has been designed for open-space living, in fact, its well-defined lines generate geometric structural continuity with striking visual impact.

One of the unique elements of the project is the exhaust hood fitted with a ground discharge system. Incorporated into the island feature, it forms an extension of this while also acting as a spatial partition.

The work plan has been designed to optimize the different stages of food preparation: washing, cutting and disposal of organic waste. In particular, a sliding board for cutting food (vegetables, fruit etc..) is installed in a spot easily accessed from each end of the kitchen, with an outlet ramp for immediately removing, washing and conveying waste products into specific trash compactors.

Moreover, retractable elements have been installed on the workbench, designed to enhance the housing of utensils that are made available to user by automated devices as required.

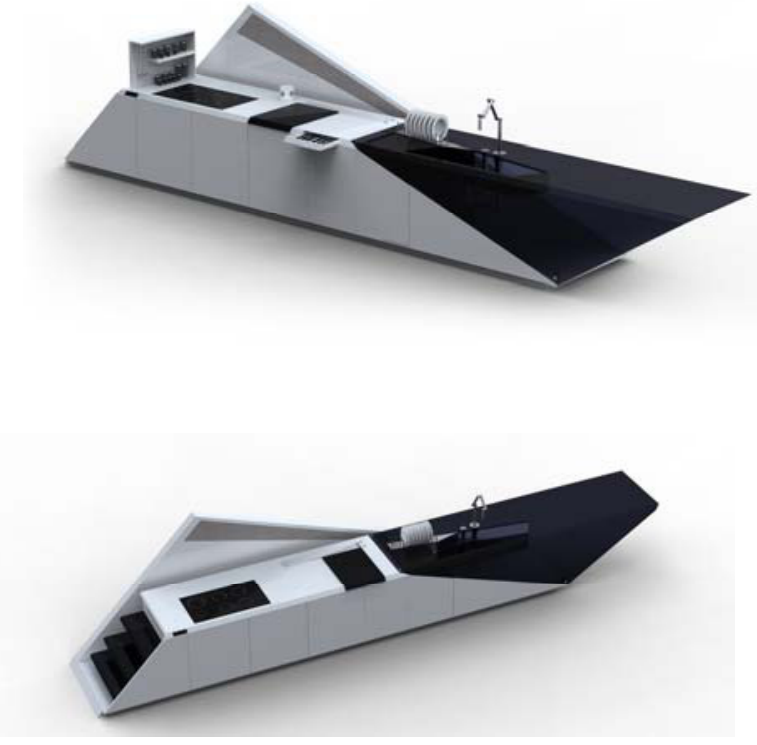

Figure 2. Vega, design by Alessia Brischetto

\subsection{Sixties follies: kitchen programme for open space}

High quality materials, innovative design, shelves instead of wall units, floating bottle: these are the features of this kitchen programme for open space. The project is aimed at demanding users and experts in the use of the kitchen. The steel worktop is one of the main expression of the high professionalism of this kitchen project.

Feature is the cancellation of the wall units, replaced by a folded aluminum profile that winds like a ribbon on the wall, serving as both bookshelf and shelf, and that becomes a link between kitchen and living area. The bases are available with doors and pull-out baskets and equipped, offering ample space for storage.

Particular attention was paid to ergonomics and sustainability of the washing area, consisting of a super-equipped kitchen sink and a pull-out faucet, which when closed is flush with the worktop. The sink is equipped with a set of functional covers, such as cutting boards and trivets, and again colanders and other accessories for washing vegetables. 

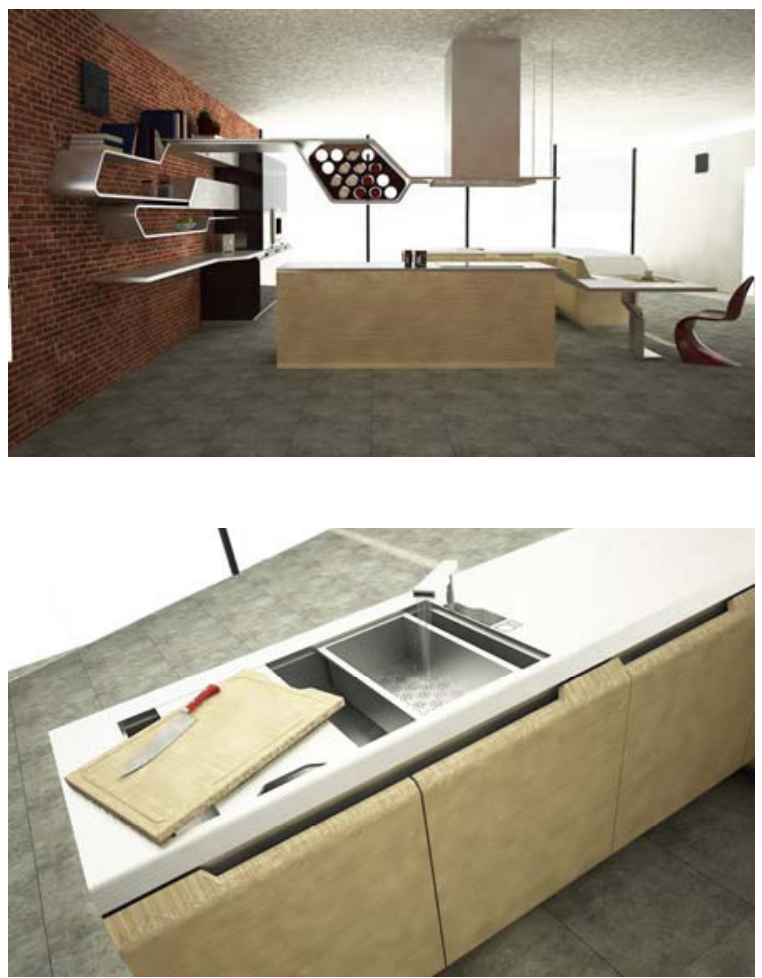

Figure 3. Sixties Folies, design by Chiara Daniele

\subsection{4 concept: compact kitchen equipment for small living spaces.}

This proposal for a compact and minimal kitchen, suitable for small domestic environment, relies on versatility to contain the essential functions within a contained, but luxurious, high-tech equipment.

Excellence in manufacturing, technology and materials, is expressed in its essential and contemporary design.

The worktop is very versatile and can be used also to close the functional components, like sink, cooking etc., in order to obtain a clean and simple piece of furniture, that fits discreetly inside a small and multifunctional domestic space.

To minimize the volume, everything superfluous has been eliminated.

The modules are suspended to facilitate cleaning and usability of the product.

This kitchen programme offers also a solution of a silicon sink with the drainer floor in Corian: when not using, the sink can be compacted within the worktop, in order to use the drainer floor for food processing.
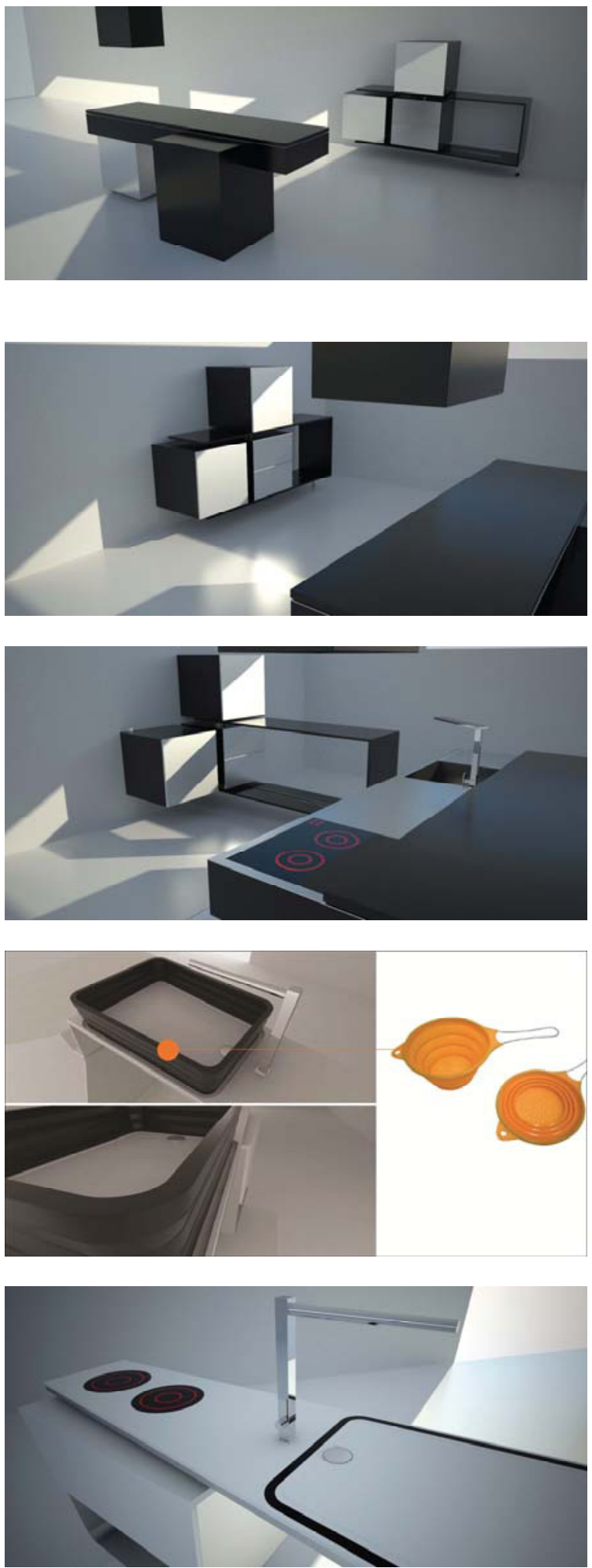

Figure 4. 334, design by Alberotanza, Madami, Malhotra 


\subsection{Cover: high flexible kitchen system}

Cover is a kitchen programme which aims at maximum ergonomics and flexibility.

The wall units and the lights can be moved along a steel track, depending on your needs. The hood is directional.

This kitchen system suites to any space and environment, thanks to a revolving worktop, that can be shaped according to the domestic space.

To expand the worktop, have been added shelves that run along it.

The sink includes a special basket for biowaste, located at the center of the two tubs for washing.

To fit users of different heights, the wall units are open vertically, scroll down through the hydraulic pistons.
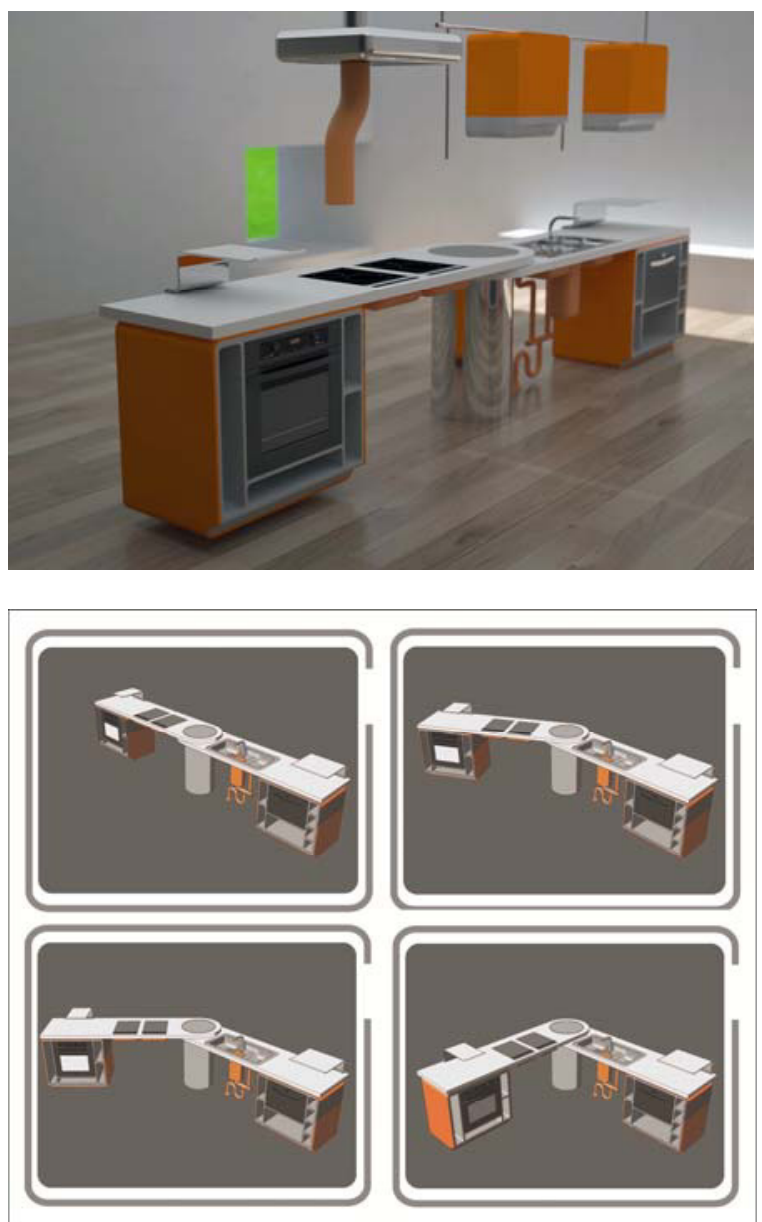
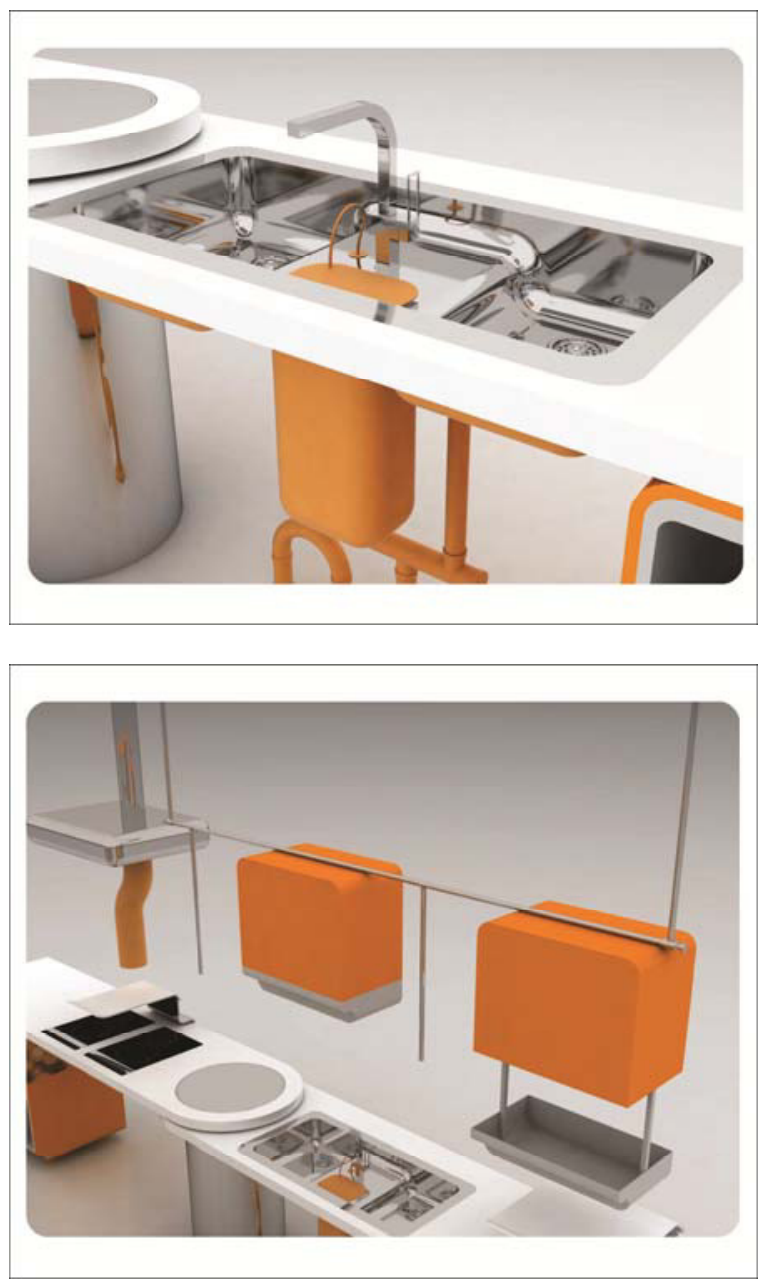

Figure 5. Cover, design by Biagini, Cogno, Lampiasi, Pastore

\subsection{Hybrid hob powered by biogas}

This project is part of a kitchen system and is a possible solution to mediate between energy consumption and environmental sustainability.

The study stems from the fact that the energy power of organic waste, produced every day in the kitchen, can be used primarily for the production of biogas and secondly as a fertilizer.

Hence the idea of a built-in appliance that integrates the function of cooking to the production of biogas and compost, through the union into a single product of a hob and a digester of organic waste. The digester uses anaerobic digestion's system. 

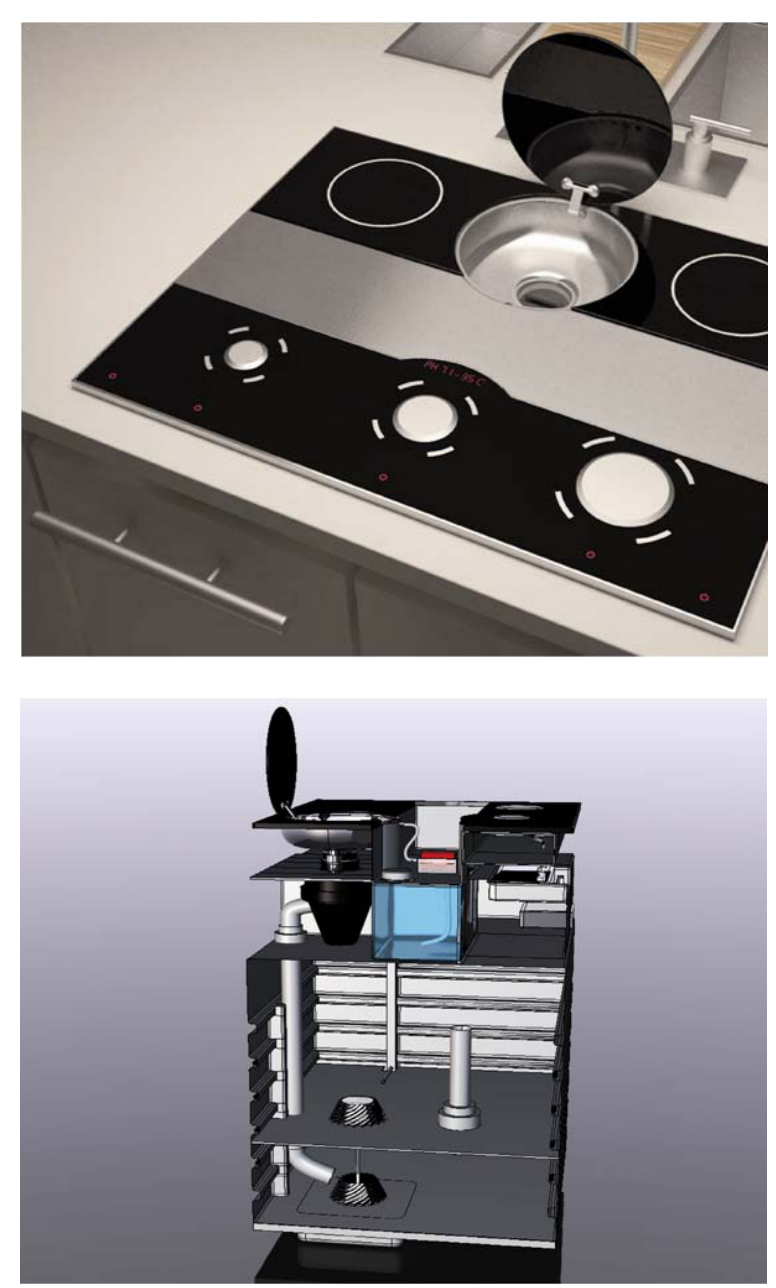

Figure 6 . Hybrid hob powered by biogas, design by Giacomo Guerrini

Not able to guarantee the continuity of biogas supply, the hob has an hybrid energy system to cook food: biogas and induction.

This innovative hob, required to carry out a perceived usability testing of the product, with some selected users, to setup the current configuration. In particular, the test was focused on the value of the reliability and accessibility of the product.

The hob is divided in three areas: the front area has three biogas burners; the central area consists of a cutting board for food processing and the subsequent discharge of the organic parts to the waste digester; the back has two induction areas and a steel compartment for release of organic waste. The funnel, that leads directly into the waste digester, located under the worktop, can also weigh the waste input and operate an electronic pump to deliver the water required by the amount of waste input.

The control system of the hob and of the waste digester is based on a touch sensitive technology.

\subsection{Modulo: a new design concept for kitchen taps}

"Modulo" consists of a range of kitchen taps, conceived within a broader survey for innovation in the kitchen environment.

The aim of this concept was to address the issue of how a kitchen tap can save water and allow the user to learn how not to waste water by exploiting a 'nudge' strategy that stimulates greater awareness of water-saving behaviour.

Each tap contains a digital water meter that displays real-time consumption. The LCD or work plan projection allows the users to be aware not only of the amount of water consumed daily in the kitchen, but also to compare their daily consumption with average consumptions of similar households, thus stimulating a sort of positive water-saving competitiveness with extremely positive consequences on the family economy and energy savings for the environment.

A tap model has also been designed with an electronic flow sensor, a great water saver although still not widely used in private homes. It has a button to activate a drinking water purification filter.

If the house is equipped with a centralized home automation system, consumption data can be recorded and accessed by users.

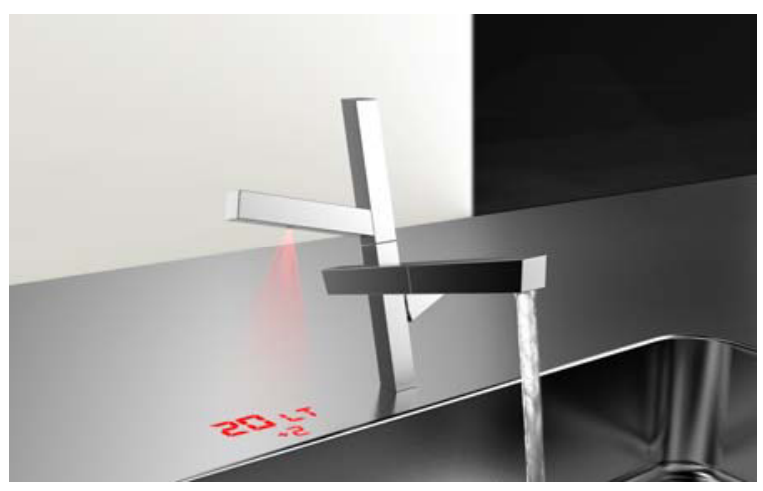

Figure 7. Modulo, design by Spring Design 


\section{References}

[1] L. Bandini Buti, Ergonomia olistica, il progetto per la variabilità umana, Franco Angeli, Milano 2008

[2] P.Bertola, E.Manzini, Design Multiverso, Polidesign, Milano 2006

[3] E.Manzini, F. Jegou, Quotidiano sostenibile. Scenari di vita urbana, Ambiente, Milano 2003

[4] E. Manzini, C. Vezzoli, Lo sviluppo di prodotti sostenibili, Maggioli, Rimini 1998, 2004

[5] G. Mantovani, Ergonomia, lavoro, sicurezza e nuove tecnologie, Il Mulino, Bologna 2000

[6] D. Norman, Emotional Design, Basic Books, New York, 2004

[7] D. Norman, Living with complexity, The MIT Press, Cambridge, Massachusetts, 2010

[8] J. Rubin, Handbook of usability testing: how to plan, design and conduct effective tests, John Wiley \& sons, New York 1994

[9] F. Tosi, Ergonomia, progetto, prodotto, Franco Angeli, Milano 2005

[10]F. Tosi, Ergonomia e progetto, Franco Angeli, Milano 2006

[11]I. McClelland, "Product assessment and user trials", in: Wilson J.R. e Corlett E.N., Evaluation of Human Work, Taylor \& Francis, Londra - Philadelphia 1995

[12]R. Verganti, Design driven innovation, Etas, Milano 2009

[13]J. Zink Klaus, Corporate sustainability as a challenge for comprehensive management, Physica-Verlag, 2008 